Biologisches Institut der Universität Stuttgart

\title{
Physiology of Ribohexulose (D-Allulose) and Allitol in Itea Plants
}

\author{
Ulrich Kull and Claudia Baitinger-HaArdt
}

With 3 figures

Received October 19,1976 - Accepted November 18, 1976

\section{Summary}

The contents of soluble carbohydrates and of starch in barks and leaves of Itea virginica were investigated during the course of a year. The predominant sugar is always ribohexulose ( $=\mathrm{D}$-allulose). In the barks its maximum content is in winter and in summer. The amount of the polyol allitol is high during the summer in barks and leaves. The content of starch shows only minor variations. In a starvation experiment, after six days of permanent darkness, the amount of ribohexulose is not considerably lowered whereas all other soluble carbohydrates including allitol have almost disappeared. From the labelling of the soluble carbohydrates after short periods of photosynthesis in ${ }^{14} \mathrm{CO}_{2}$ a rapid synthesis and turnover of ribohexulose can be seen in the light.

Ribohexulose has probably taken over storage functions which in other plant species are performed by starch. The same may be true in diverse species for other soluble carbohydrates, the amounts of which show a maximum in the summer together with the usual winter-maximum. Ribohexulose is a partially inert storage compound and to some extent behaves similarly to the polyol dulcitol in Evonymus, However, allitol in Itea is metabolically active and is rapidly synthesized in the light and converted in the dark.

Key words: ribohexulose, allitol, carbohydrate storage, Itea virginica.

\section{Introduction}

During investigations on polyols in leaves, Plouvier (1959) isolated allitol from species of the genus Itea (Saxifragaceae s.l.; Iteaceae/Saxifragales sensu TAKHTAJAN, 1973). Subsequently the coexistence of the ketohexose $\mathrm{D}$-allulose $=$ ribohexulose in Itea was established (Hough and STACEY, 1963). Both these carbohydrates hitherto are only known from this one genus and play an important role as storage sugars of these plants. The content of other sugars and of starch in the leaves of Itea is relatively low (Hough and STACEY, $1966 \mathrm{~b}$ ). Up to now the changes of the content of ribohexulose and allitol during the year have never been investigated. Therefore, we examined their periodical changes in the species Itea virginica. In a darkening experiment the character of ribohexulose and allitol as true reserve compounds was investigated. Supplementary to the experiments described by HougH and STACEY (1966 a, b) and Hough et al. (1973) the labelling of soluble carbohydrates after 
short term photosynthesis with ${ }^{14} \mathrm{CO}_{2}$ was determined. From the labelling-kinetics it should be possible to recognize turnover rates and thereby help to clarify the roles of ribohexulose and allitol as reserve and storage carbohydrates.

\section{Materials and Methods}

\section{Plants}

Young twigs were gathered mid-month at monthly intervals all the year and always at 11 a.m. from a shrub of Itea virginica L. growing in the open air in the Botanical Garden. Bark and vegetative leaves were isolated, frozen, and lyophilized.

\section{Methods}

The sugars were separated and estimated quantitatively by paper chromatographic methods (Jeremias, 1958, 1965; Kull, 1965). Allitol was measured by the method of SeYBOLD (1969) for the quantitative estimation of polyols. Ribohexulose and allitol were not available for calibration, so fructose and sorbitol, respectively, were used as standards. The percentage error with regard to allitol is probably high.

The quantitative analysis of starch after extraction and enzymatic cleavage with amyloglucosidase according to DEKKER and RICHARDS (1971) was performed with glucose oxidase (Fleming and Pegler, 1963). This method proved to be very suitable for the starch of the leaves, but for bark the measurements did not agree well with microscopic examinations; a result which corresponds to the data of BAILEY and MACRAE (1973). Methods based upon the colouring of starch by iodine are unfavourable for quantitative estimations in tissues (comp. the discussions in Nótzel, 1975). Therefore, we also measured the starch content of the bark by the method of MCCREADY et al. (1950; extraction with perchloric acid, estimation of glucose by anthrone), according to the concentrations communicated by HaNSEN and Moller (1975). This method also causes erroneous results when partly lignified tissues are investigated (EBELl, 1969; Comp. BreckLE and Kull, 1973). Yet the results we obtained using this method are in better agreement with the microscopic findings and are presented in fig. 1.

Photosynthesis of young twigs (with 5 to 7 leaves and green bark; comp. Hough and StACEY, 1966) in ${ }^{14} \mathrm{CO}_{2}$ was carried out in a desiccator. Prior to this the leafy twigs were kept in a moist chamber for $1 \mathrm{hr}$ to obtain optimal opening of stomata. Then, after establishing a limited partial vacuum in the desiccator, the $\mathrm{CO}_{2}$ was set free from $10 ! 1 \mathrm{Ci}$ $\mathrm{NaHCO}_{3}$ (diluted with cold $\mathrm{NaHCO}_{3}$ ) using $5 \% \mathrm{H}_{2} \mathrm{SO}_{4}$. Immediately after the normal pressure was re-established and the desiccator exposed to full sunlight for different times. Following different periods of photosynthesis the leaves were rapidly detached, cut into small pieces and extracted with boiling ethanol (method of BECK et al., 1968). Each feeding experiment was repeated; all experiments were carried out in June. The separation of labelled compounds was accomplished by two-dimensional chromatography according to the methods of VAN SCHERPENBERG et al. (1965) and preferably using the combination phenol/butanol-propionic acid-water as solvent. The labelled compounds were localized by autoradiography and counted using a windowless $\mathrm{CH}_{4}$-flow-counter with wide opening (SENSER and KANDLER, 1967; BeCK et al., 1968).

\section{Results}

The variations of carbohydrate content in barks of young twigs of Itea virginica during a year are presented in fig. 1 . Besides the sugars shown there we always found 
Itea barks

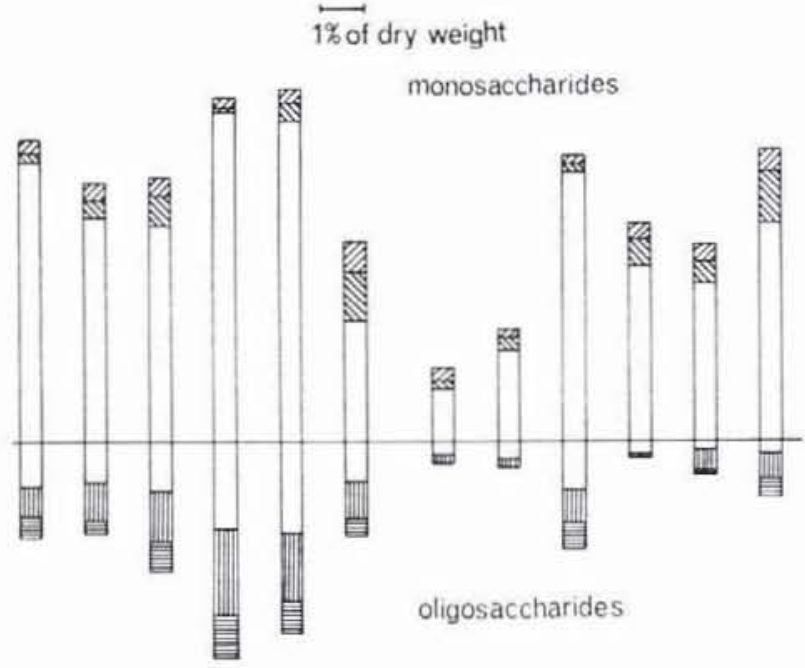

allitol

Fig. 1: Contents of sugars, allitol, and starch (as \% of dry weight) in barks of Itea virginica during the course of a year measured at monthly intervals. Monosaccharides from top to bottom: glucose, fructose, ribohexulose; oligosaccharides from top to bottom: sucrose, raffinose, stachyose.

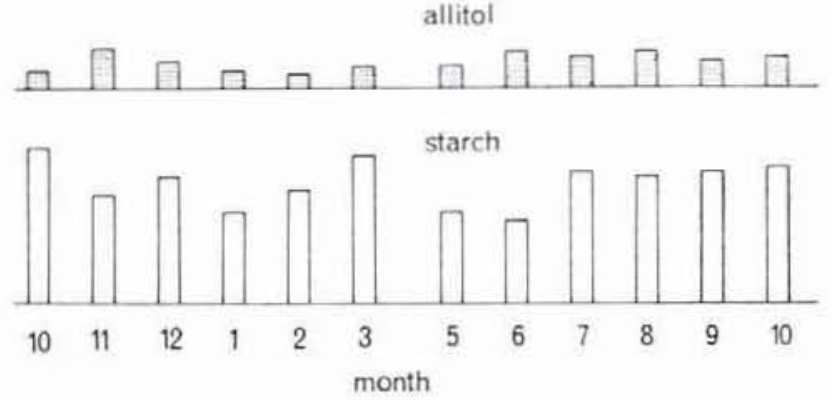

traces $(<0.1 \%$ of dry weight) of sedoheptulose in the barks and in some samples maltose also. The maximum amount of soluble carbohydrates is reached as usual in the winter (in January $>12 \%$ on a dry weight basis). The low sugar content during the summer months lasts from May till September; only the determinations in July, shortly after flowering of the plant, show some deviation. The variations in ribohexulose content during the year are very distinct with a maximum in winter, low amounts during May/June and again high concentrations during the summer months after flowering. The oligosaccharides, that is sucrose and the raffinose-sugars raffinose and stachyose, show the typical time-course with highest content in winter and lowest during the summer. The amount of allitol is high during early winter and during summer; the lowest quantities are present in late winter and spring. The content of starch shows only minor variations throughout the year. No distinct minimum in winter and no clearly marked increase in spring or summer can be seen.

The alterations of carbohydrates in the leaves of Itea are shown in fig. 2 . Additionally, sedoheptulose and maltose could be identified as traces $(<0.1 \%)$ in most samples. The occurrence of a trace of xylose in November seems to be caused by senescence. The total content of sugars rises during the spring, declines in summer and again moves to a higher level near the end of the vegetation period. These alterations are essentially caused by ribohexulose. Allitol reaches its highest content during the 

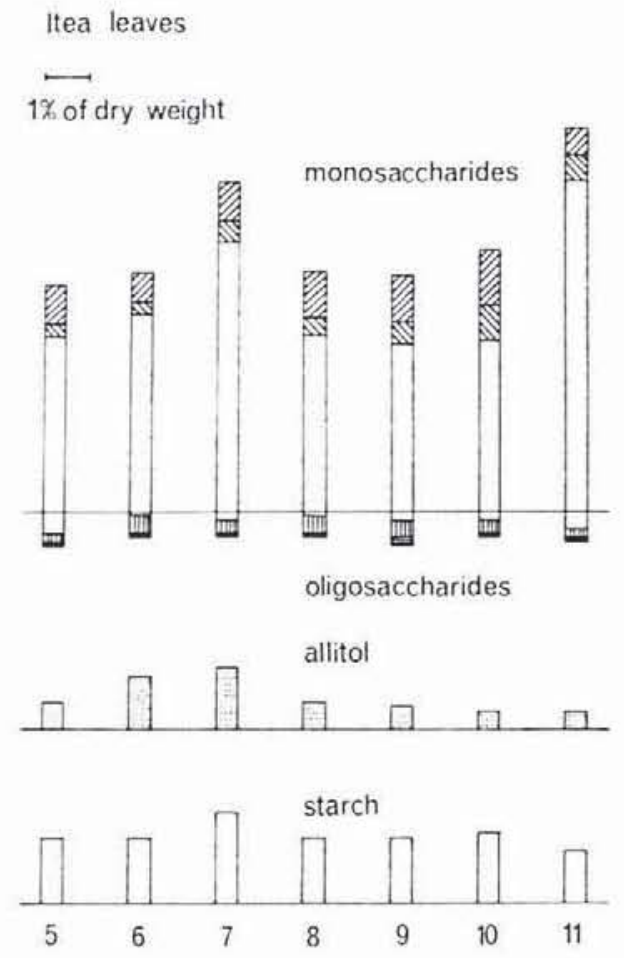

Fig. 2: Contents of sugars, allitol, and starch (as $\%$ of dry weight) in leaves of Itea virginica during a vegetation period measured at monthly intervals. Symbols as in fig. 1.

summer months. From May to August an additional spot on the chromatograms was found which reacts as a polyol. The suspicion that it might be a polyol-phosphate (SEybold, 1969) could not be verified. The amount of starch in the leaves shows only minor variations with a highest value in July.

In plant species containing sedoheptulose the content of this ketosugar is raised by feeding ribose (RENDIG and MсСомB, 1962). Therefore, in an analogous series of experiments in August young Itea twigs were fed D-erythrose (solution of $3 \%$ ) after 24 hours predarkening. After 24 hours of feeding the carbohydrate content of the leaves was investigated. The results are shown in table 1. It should be emphasized that in twigs fed with

Table 1: Carbohydrate content of leaves of Itea virginica after feeding D-erythrose $(3 \%$ solution) for 24 hours following 24 hours pre-darkening (as \% of dry weight).

\begin{tabular}{lccc}
\hline Carbohydrate & $\begin{array}{c}\text { Controls } \\
48 \text { hours } \\
\text { darkness }\end{array}$ & $\begin{array}{c}\text { Erythrose fed } \\
\text { after } 24 \text { hrs } \\
\text { darkness }\end{array}$ & $\begin{array}{c}\text { Controls: natural } \\
\text { conditions of } \\
\text { light periodicity }\end{array}$ \\
\hline erythrose & - & 0.1 & - \\
ribohexulose & 4.6 & 4.4 & 3.7 \\
fructose & 0.2 & 0.4 & 0.4 \\
glucose & 0.3 & 0.8 & 0.7 \\
sucrose & 0.2 & 0.4 & 0.3 \\
raffinose & 0.2 & 0.3 & 0.4 \\
stachyose & 0.3 & 0.2 & 0.2 \\
allitol & 0.15 & 0.4 & 1.0 \\
starch & 1.2 & 1.5 & 1.5
\end{tabular}

Z. Pflanzenphysiol. Bd. 82. S. 301-309. 1977. 
erythrose only traces of this sugar are present in the leaves. The amount of starch is lowered only a little in controls darkened for 48 hours. It is identical in controls from normal light conditions and with leaves from the fed twigs.

In one set of experiments (starvation-experiment), young twigs were kept permanently in the dark at the beginning of July for different times. Afterwards the carbohydrate content of the leaves was investigated. In fig. 3 a gradual decrease of oligosaccarides and of glucose and fructose may be seen. After 144 hours of darkness the amounts of these sugars are no longer measurable, as is the case for allitol. The content of ribohexulose rises at the beginning and after 48 hours of darkness it is distinctly higher than in controls. The same can be seen from the controls in the erythrose-feeding experiment. In prolonged darkness a slow decrease is recognizeable. After 6 days in permanent darkness the content is nearly as high as at beginning of the experiment. The diminution of starch in the darkened leaves takes place very slowly.
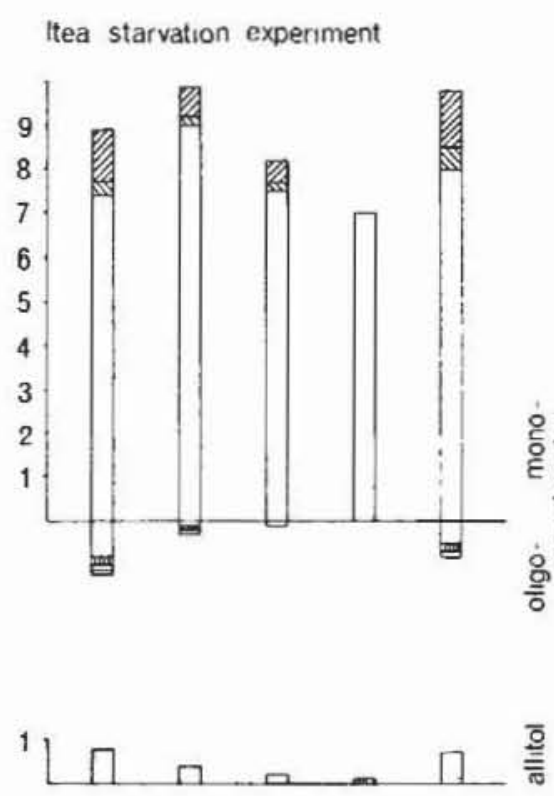

Fig. 3: Contents of sugars, allitol, and starch (as $\%$ of dry weight) in leaves of Itea virginica kept permanently in darkness for different periods. Symbols as in fig. 1. co = controls; co $144=$ controls after $144 \mathrm{~h}$ natural light periodicity.

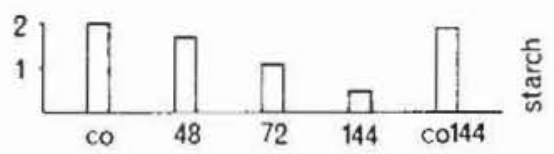

The variations of ribohexulose during a year's course point to its importance as a storage and reserve carbohydrate, but the starvation experiments do not support this view. Therefore, some labelling experiments were carried out extending the experiments of Hough and STACey (1966 a, b). To attempt to determine the labelling-kinetics of sugars, shorter periods of photosynthesis in ${ }^{14} \mathrm{CO}_{2}$ were employed and in contrast to HOUGH and STACEY the radioactivity of all sugars 
Table 2: Distribution of labelling in ethanol-soluble compounds of Itea leaves after photosynthesis in ${ }^{14} \mathrm{CO}_{2}$ for different periods, expressed as percent of total activity of chromatograms.

\begin{tabular}{lrrrr}
\hline \multicolumn{1}{c}{ Compound } & \multicolumn{4}{c}{ min photosynthesis in ${ }^{14} \mathrm{CO}_{2}$} \\
& 5 & 10 & 20 & 30 \\
\hline ribohexulose & 22.0 & 42.6 & 48.0 & 31.6 \\
allitol & 6.4 & 10.6 & 18.7 & 20.9 \\
fructose & 2.5 & 8.5 & 5.1 & 5.8 \\
glucose & 2.5 & 5.9 & 4.1 & 4.2 \\
sucrose & 2.0 & 4.1 & 7.8 & 12.0 \\
maltose & 0.9 & 0.9 & 0.2 & 0.1 \\
raffinose & 0.2 & 1.8 & 2.0 & 2.0 \\
stachyose + galactinol & 0.2 & 4.7 & 5.8 & 5.9 \\
sugar phosphates + & & & & \\
phosphoglyceric acid & 38.5 & 12.0 & 5.9 & 6.0 \\
compounds not identified & 24.8 & 8.9 & 2.4 & 11.5
\end{tabular}

present was measured. The results (average values of two sets of experiments which gave similar results) are shown in table 2. As expected, the labelling of sugar-phosphates and phosphoglyceric acid (expressed as percentage of total activity) decreases with an increasing time of photosynthesis. For sucrose we find a nearly linear increase in labelling up to the end of the experiments ( $30 \mathrm{~min})$. This is characteristic for sucrose-storing leaves; the content and the percentage of activity is, however, much lower than usual. Raffinose, stachyose and galactinol behave as described by SeNSER and KANDLER (1967). The labelling of allitol increases up to the end of the experimental time also, but the increase is retarded towards the end. Ribohexulose shows the highest activity of all carbohydrates. It is more rapidly labelled than sucrose. The activity, expressed as percentage of total acitity, rises up to $20 \mathrm{~min}$ and then declines. Glucose and fructose both show a rather high activity. The labelling of these sugars increases only up to $10 \mathrm{~min}$ and then decreases, indicating a rapid turnover.

\section{Discussion}

During the whole year ribohexulose is the predominant sugar in Itea. Its content is considerably higher than measured by Hougr and StACEY (1966 a, b); this was already suspected by these authors. The variations of the amounts of soluble carbohydrates during the course of a year are mainly caused by the fluctuations of ribohexulose. The behaviour of ribohexulose may be compared to that of sedoheptulose in Saxifraga decipiens (KULL, 1965). In this species sedoheptulose is the major storage carbohydrate with maximum storage during the winter and during and after flowering in late spring. Similarly, as HopF and KANDLER (1976) have shown, 
in Aegopodium the oligosaccharide umbelliferose is accumulated in summer after fruit-ripening and, as usual, during the winter months. Contrary to the behaviour of ribohexulose, starch has only minor fluctuations in bark and in leaves. From these data and from the labelling experiments of Hough and Stacer (1966 b) an inferior role may be attributed to starch in carbohydrate storage and metabolism of Itea. Probably in this genus ribohexulose has taken over from starch in storage functions and therefore shows a high content during summer instead of the usual summer-maximum of starch; it also shows the lowest amount in barks during and shortly after leaf development. A shift of function of starch to a sugar resp. polyol is also probable for sedoheptulose in Saxifraga decipiens and for dulcitol in Evonymus europaeus (SEYBOLD, 1969). Unfortunately, there are no data for Aegopodium regarding starch. It must be noted that in different species the same sugar may behave differently. For example, sedoheptulose in Sempervivum has its only maximum during the winter, maintaining high osmotic values which probably contribute to avoidance of frost injury (KulL, 1967). The same function seems to be attributable to ribohexulose concerning its winter maximum.

The content of ribohexulose does not rise by feeding erythrose but the amounts of glucose, sucrose and, less distinctly, of allitol, are maintained. Concerning the metabolism of ribohexulose nothing can be concluded from this experiment.

The behaviour of ribohexulose during the starvation-experiment appears to be contrary to our conclusions drawn from its content over the course of a year. Even after 6 days of permanent darkness the amount of ribohexulose is not considerably lowered, whereas the other soluble carbohydrates have almost disappeared. The slow decrease of the starch content in this experiment agrees with earlier findings of SEybold (1968) and of Vignes (1972). The increase of the ribohexulose content in the beginning of darkness supports the data of Hough and Stacey $(1966 \mathrm{a}, \mathrm{b})$. The character of ribohexulose as a true reserve compound is questioned by the starvation-experiment, in which its behaviour somewhat resembles that of hamamelitol in Primula clusiana (Sellmair and Kandeler, 1970) and even more that of dulcitol in Evonymus species according to the data of SEYBold (1968) and Bliss et al. (1972). However, our labelling experiments show that ribohexulose is rapidly synthesized during photosynthesis. Also a rapid conversion to allitol occurs in the light, and the reverse process is operative in the dark (Hough and STACEY, $1966 \mathrm{a}$, b). In contrast, ribohexulose is not metabolised to a considerable extent in the dark and its behaviour is, therefore, rather unique. It is not metabolically inert as Sellmair and Kandere (1970) found for hamamelitol, and further it is not degraded in the dark. Only one similar case has been reported in the literature, and that is for dulcitol in Evonymus (Seybold, 1968 and Bliss et al., 1972). The function of this physiological behaviour is not clear. Perhaps it is to maintain a distinct osmotic value (GörING, 1970), possibly in connection with ecological adaptation. It is also not yet fully clear through which mechanism the ribohexulose level is maintained. From our experiments and those of Hough and Stacey (1966 b) it seems most 
probable that an inhibition of its catabolism is operating during darkness. This would be analogous to the findings of Burss et al. (1972) concerning dulcitol.

The labelling-intensities of fructose and glucose are rather high in Itea, compared e.g. with the data of van Scherpenberg et al. (1965). Probably these sugars are precursors for ribohexulose synthesis (comp. Hough et al., 1973). However, the rapid and intense labelling of ribohexulose seems best to be explained by assuming that a synthesis from precursors is occurring directly from the photosynthetic cycle.

Allitol is readily metabolised by Itea and is not a relatively inert final product as is assumed for dulcitol in Evonymus. In our labelling experiments the activity increases with increasing time; according to the data of Hough and STACEY (1966 b) this increase would be continued over a longer experimental time. The high content of allitol in leaves during the summer is connected with the period of intense photosynthesis. This behaviour is similar to that of different polyols in leaves of several other species, including dulcitol in Evonymus (SEYbold, 1969). On the other hand, the variations of sorbitol in Prunus leaves (DE Villiers and Meynhardt, 1972) are different. Allitol does not take part in the sugar accumulation during the winter months. Seybold (1969) in investigations of several species showed that in some species polyols contribute maximally to the sugar content during the winter; in others they do not. From the starvation experiment it can be seen that allitol is a true and readily convertible reserve material. This agrees with data from some other polyols; especially for sorbitol in Malus, but not with those for dulcitol in Evonymus (SEYBoLd, 1968).

In Itea the polyol allitol is a metabolically active carbohydrate but the ketose ribohexulose is partially inert and behaves rather similar to the polyol dulcitol in Evonymus. In this connection it may be noted that TAKHTJAN (1973) states that the Celastrales are probably phylogenetically derived from primitive ligneous Saxifragales, to which the Iteaceae belong.

Regarding the oligosaccharides, the only remarkable point is a high concentration of these sugars in July, which corresponds with the time of flowering and the beginning of seed-set.

\section{Acknowledgements}

The authors gratefully acknowledge the help of Miss BARBARA KüHN and the correction of the English text by Dr. E. Thomas and Miss A. BARKer. The investigations were supported by a grant from the DFG.

\section{References}

Batley, R. W., and J. C. MACrae: FEBS Letters 31, 203 (1973).

Beck, E., J. Sellmair, and O. Kandler: Z. Pflanzenphysiol. 58, 434 (1968).

Buiss, C. A., N. W. Hamon, and T. P. Lukashewski: Phytochemistry 11, 1705 (1972).

Breckle, S. W., and U. Kull: Bot. Jahrb. Syst. 93, 539 (1973).

DekKkeR, R. F. H., and G. N. Richards: J. Sci. Food Agric. 22, 441 (1974).

Ebel.t, L. F.: Phytochemistry 8, 25 (1969).

Z. Pflanzenphysiol. Bd. 82. S. 301-309. 1977. 
Fleming, I. D., and H. F. Pegler: Analyst (London) 88, 967 (1963).

Góring, H.: Biol. Zentralbl. 89, 343 (1970).

Hansen, J., and I. Moller: Anal. Biochem. 68, 87 (1975).

Hopf, H., and O, Kandler: Biochem. Physiol. Pflanzen 169, 5 (1976).

Hough, L., and B. E. StaceY: Phytochemistry 2, 315 (1963).

- - Phytochemistry 5, $171(1966$, a).

- - Phytochemistry S, 215 (1966, b).

Hough, L. P., N. Shankar IYer, and B. E. Stacey: Phytochemistry 12, 573 (1973).

Jeremias, K.: Planta 52, 195 (1958).

- Planta 65, 73 (1965).

Kull, U.: Beitr. Biol. Pflanzen 41, 231 (1965).

- Ber. dtsch. Bot. Ges. 80, 187 (1967).

McCready, R. M., J. Guggolz, V. Silvieira, and H. S. Owens: Analyt. Chem. 22, 1156 (1950).

Nótzel, E.: Diss. Univ. Innsbruck (1975).

Plouvier, V.: C. R. Acad. Sci. (Paris) 249, 2828 (1959).

Rendig, V. V., and E. A. McСomB: Arch. Biochem. Biophys. 99, 409 (1962).

Scherpenberg, H. van, W. Gróbner, and O. Kandler: Beitr. Biochem. Physiol. Naturstoffe (K.-Mothes-Festschrift), 387, VEB G. Fischer, Jena, 1965.

Sellmair, J., and O. Kandler: Z. Pflanzenphysiol. 63, 65 (1970).

Senser, M., and O. Kandler: Z. Pflanzenphysiol. 57, 376 (1967).

Senser,, M., P. Dittrich, O. Kandler, A. Thanbichler, and B. Kuhn: Ber. disch. Bot. Ges. 84, 445 (1971).

Seybold, S.: Diss. Univ. Stuttgart (1968).

- Flora, Abt. A, 160, 561 (1969).

Takhtajan, A.: Evolution und Ausbreitung der Blütenpflanzen. G. Fischer, Stuttgart, 1973.

Vignes, D.: C. R. Acad. Sci. (Paris), Ser. D, 275, 1375 (1972).

Vil.Liers, O. T. DE, and J. T. Mrynhardt: Agroplantae 4, 93 (1972).

Dr. Ulrich Kull, Biologisches Institut der Universität Stuttgart, Ulmer Straße 227, D-7000 Stuttgart 60. 